\title{
Barium selenate supplementation and its effect on intramammary infection in pasture-based dairy cows
}

\author{
A. Ceballos, ${ }^{*} \dagger^{1}$ J. Kruze,‡ H. W. Barkema,§\# I. R. Dohoo, ${ }^{*} \|$ J. Sanchez, ${ }^{*} \|$ D. Uribe,‡ J. J. Wichtel, $\dagger$ \\ and F. Wittwerף \\ *Departamento de Sistemas de Producción, Universidad de Caldas, Manizales, Colombia \\ †Department of Health Management, Atlantic Veterinary College, University of Prince Edward Island, Charlottetown, Prince Edward Island, \\ C1A 4P3 Canada \\ ¥Microbiology Department, Faculty of Sciences, Universidad Austral de Chile, Valdivia, Chile \\ $\S$ Department of Production Animal Health, Faculty of Veterinary Medicine, University of Calgary, Calgary, Alberta, T2N 4N1 Canada \\ \#Department of Reproduction, Obstetrics and Herd Health, Faculty of Veterinary Medicine, Ghent University, Merelbeke, Belgium \\ ॥Centre for Veterinary Epidemiological Research, University of Prince Edward Island, Charlottetown, Prince Edward Island, C1A 4P3 Canada \\ IDepartment of Veterinary Clinical Sciences, Faculty of Veterinary Sciences, Universidad Austral de Chile, Valdivia, Chile
}

\section{ABSTRACT}

A significant proportion of cattle receive inadequate dietary Se because of its low content in soils and pastures of various regions of the world. Several economically important diseases in dairy cows, such as mastitis, have been associated with Se deficiency. The objective of this study was to evaluate the effect of a single injection of a long-acting form of Se at drying off on the risk and incidence rate of new intramammary infections and on milk somatic cell count in the subsequent lactation in pasture-based dairy cows. Forty-nine Chilean Holstein-Friesian cows were fed a diet containing $<0.05 \mathrm{mg}$ of $\mathrm{Se} / \mathrm{kg}$ of ration dry matter. During the dry period, cows were allocated to 1 of 2 groups, a supplemented $(\mathrm{n}=24)$ group treated with a single subcutaneous injection of barium selenate 2 mo before calving and a control group $(\mathrm{n}=25)$ that remained unsupplemented. Duplicate foremilk samples were aseptically collected within $6 \mathrm{~d}$ after calving and every 2 wk until drying-off for bacteriological culture. Milk samples were also collected monthly for somatic cell count evaluation. Blood samples were collected before treatment and at 30,90, 180, and $270 \mathrm{~d}$ after treatment for analysis of blood glutathione peroxidase (GPx) activity. The activity of glutathione peroxidase was higher in supplemented cows $30 \mathrm{~d}$ after the injection until the end of the study. The risk and incidence rate of new intramammary infections was not affected by supplementation. A progressive increase in somatic cell count was observed throughout lactation, but there was no effect of supplementation. In conclusion, a onetime injection of barium selenate 2 mo before calving

Received May 21, 2009.

Accepted December 7, 2009.

${ }^{1}$ Corresponding author: aceballos@upei.ca in these pasture-based dairy cows did not affect udder health in the subsequent lactation, indicating that Se basal intake was adequate for preventing subclinical mastitis in pasture-based cows in southern Chile.

Key words: selenium, intramammary infection, somatic cell count, pasture

\section{INTRODUCTION}

Subclinical and clinical mastitis are associated with decreased profitability caused by decreased milk yield, cost of treatments, early culling, extra labor, discarded milk, and increased rate of cow replacement, making mastitis economically the most important health issue for the dairy industry (Huijps et al., 2008). The immune response mechanisms of the udder effectively deal with contagious or environmental pathogens much more frequently than mastitis occurs (Burton and Erskine, 2003); however, virtually all effectors of the immune response, such as phagocytosis, antibodies, and cell-mediated cytotoxicity, are influenced by the nutritional status of the cow and thus nutrition can play an important role in the outcome of IMI (Smith et al., 1997; Ibeagha et al., 2007).

The influence of micronutrients, Se in particular, on the immune response and udder health has been recognized since the early 1980s (Smith et al., 1984, 1985). Providing insufficient Se in dairy cow rations results in a reduced concentration of Se in blood and milk (Maus et al., 1980) and downregulation of the expression of many selenoproteins, including glutathione peroxidase $(\mathbf{G P x})$ and thioredoxin reductase, which act as antioxidants with roles in defense of the mammary gland (Sordillo and Aitken, 2009). Restricted Se intake is known to decrease the bactericidal capacity of bovine neutrophils and inhibit lymphocyte proliferation (Grasso et al., 1990; Ndiweni and Finch, 1995). 
North American studies have tended to indicate that low Se intake is associated with a high number of infected quarters at calving and a high SCC (Smith et al., 1984, 1985), whereas studies in pasture-based dairy cows in New Zealand have tended to find no such relationship (Whelan et al., 1992; Grace et al., 1997). The requirement for Se for optimal immune function may be greater than that for other functions (Wichtel, 1998b; NRC, 2001). Conversely, the relatively low incidence of udder health disorders observed in pastoral systems in regions with low Se intake suggests that immune function is not always impaired in cows moderately deficient in Se, and that environmental and management factors and intake of other micronutrients such as vitamin E, may modify the requirement for Se for optimal udder immunity (Wichtel, 1998a). Consequently, the literature is unclear regarding the effect of increased Se intake on the defense mechanisms of the mammary gland, especially when experimental results derived from North American intensive production systems are compared with those from dairy cows raised in pastoral systems typical of Oceania. Up to 10-fold differences in recommended Se intakes for dairy cows between countries are reported (Grace, 1992; NRC, 2001), in part because of the inconsistencies mentioned in response to supplementation.

Methods for Se supplementation differ in their cost and practicality for supplementing pasture-based cattle (Wichtel, 1998a). Aqueous solutions for oral use (drenches), intramuscular or subcutaneous injections, and ruminal pellets have been used to provide supplemental Se to pastured animals (MacPherson and Chalmers, 1984). A single injection of barium selenate, a source allowed by the European Union for use in cattle (EMEA, 1999), provides long-duration supplementation in ruminants (Mallinson et al., 1985). An injectable depot product is clearly useful in pasture-based cattle, as only a single administration per lactation is required, ideally before calving, and does not depend on feeding a Se-fortified concentrate ration. Such a method reduces labor and decreases the risk of transient deficiencies during the grazing season. Nevertheless, the effect of a depot Se product on the incidence of new IMI and on SCC in cows raised in pastoral systems under commercial conditions has not been adequately investigated to date, or only results concerning SCC have been reported (Whelan et al., 1992). Thus, the objective of the study was to determine the effect of a single injection of barium selenate before calving on the risk and incidence rate of overall and pathogen-specific new IMI, and on SCC during lactation in pasture-based dairy cows.

\section{MATERIALS AND METHODS}

All procedures for this trial complied with current regulations for the humane care and treatment of animals, and the Commission for Animal Care and Use of the Universidad Austral de Chile.

\section{Animals and Treatments}

The trial was carried out on a commercial dairy farm in southern Chile $\left(39^{\circ} 46^{\prime} \mathrm{S}, 73^{\circ} 13^{\prime} \mathrm{W}\right)$ known to have low Se content in pasture $(<0.05 \mathrm{mg} / \mathrm{kg}$ of DM). Previous herd-level analyses of the blood GPx activity indicated a mean activity $<100 \mathrm{U} / \mathrm{g}$ of $\mathrm{Hb}$, reflecting a suboptimal Se intake (Ceballos et al., 1999). Geometric mean bulk tank SCC in the year before the start of the trial was 259,000 cells/mL.

Forty-nine clinically healthy primiparous $(\mathrm{n}=21)$ and multiparous $(\mathrm{n}=28)$ pregnant (approximately 7 mo of gestation) Chilean Holstein-Friesian cows were selected for this study. Sample size was calculated to detect a difference of 40,000 cells/mL and a reduction of $40 \%$ in the risk of new IMI between groups according to information previously reported (Smith et al., 1985). Cows were weighed before the start of the study, and their weight ranged between 540 and $620 \mathrm{~kg}$. Milk yield per lactation per cow, according to the farm records, was approximately $6,000 \mathrm{~kg}$. Cows were assigned to 1 of 2 groups stratified by parity, weight, and predicted date of calving.

Two months before the mean predicted date of calving, cows in the supplemented group $(\mathrm{n}=24)$ received a single subcutaneous injection of inorganic Se (barium selenate, Deposel, Young Animal Health Ltd., Wellington, New Zealand) at a dose of $1.0 \mathrm{mg} / \mathrm{kg}$ of live weight. Cows in the control group $(\mathrm{n}=25)$ received no treatment. The animals did not receive any other treatment that could affect their Se status.

All cows calved over an 8-wk period in the Southern Hemisphere winter (i.e., mid June to mid August). Calves were removed from cows within $2 \mathrm{~d}$ after birth. Cows were milked twice a day in a herringbone style parlor with 8 units and a high milk line, and milk yield was recorded monthly. Mastitis management included regular monitoring of milking machine function, postmilking teat disinfection, antibiotic treatment of clinical cases, and antibiotic treatment of all cows at drying-off. Throughout the dry period and lactation, both groups of cows grazed as one herd on pastures providing less than $0.05 \mathrm{mg}$ of $\mathrm{Se} / \mathrm{kg}$ of DM, comprising predominantly ryegrass (Lolium perenne) and white clover (Trifolium repens). Cows were moved daily onto 
fresh pasture. To meet nutritional requirements at the peak of lactation (NRC, 2001), the ration was supplemented with silage made from the same pasture and a commercial concentrate $(2.9 \mathrm{Mcal} / \mathrm{kg}$ and $15 \%$ of $\mathrm{CP}$ on a DM basis; Cosetan Vaca Lechera, Biomaster-IANSA, Temuco, Chile). The concentrate offered per cow was, on average, $0.25 \mathrm{~kg} / \mathrm{kg}$ of milk yield. Additionally, a Se-free mineral mix (Vetersal, Veterquimica, Santiago, Chile) was fed at a rate of $200 \mathrm{~g} / \mathrm{cow}$ per day. Water was offered ad libitum.

\section{Sampling and Data Collection}

The farmer was trained to collect milk samples aseptically from those quarters that had physical signs of clinical mastitis (any visual abnormality of milk or udder, with or without systemic signs of disease), at any stage of the study. In addition, a physical examination of the mammary gland and milk characteristics was conducted within $6 \mathrm{~d}$ after calving and whenever a milk sample was collected to detect individual quarters that were inflamed (hard, swollen, or hot) due to clinical mastitis. The first streams of milk were squirted into a dark cup to detect any abnormality such as discoloration, flakes, clots, or wateriness.

Duplicate foremilk samples $(15 \mathrm{~mL})$ for bacteriological analysis were aseptically collected from every quarter by an experienced veterinarian and technicians in the first week after calving and thereafter every 14 $\mathrm{d}$ until the end of lactation. For each quarter, the first stream of milk was discarded; the teat end was wiped to remove gross contamination and finally disinfected with a cotton swab soaked in $70 \%$ alcohol. Immediately after collection, samples were refrigerated at $5^{\circ} \mathrm{C}$ for transportation to the laboratory. Additionally, composite milk samples $(30 \mathrm{~mL})$ from each cow were collected monthly for SCC determination using potassium dichromate as preservative, kept refrigerated, and analyzed within $48 \mathrm{~h}$.

Coccygeal venous blood samples were collected from control and treated cows before treatment and at 30, 90, 180, and $270 \mathrm{~d}$ after the treatment date into heparinized vials to determine the activity of GPx.

\section{Laboratory Analyses}

Udder health status was established through clinical and bacteriological examinations of the mammary gland. Bacteriological examination was performed according to the standards of the National Mastitis Council (Oliver et al., 2004). A volume of $0.025 \mathrm{~mL}$ of milk was streaked onto one quadrant of an esculin blood (sheep) agar plate, which was kept at room temperature for $30 \mathrm{~min}$, and then aerobically incubated at $37^{\circ} \mathrm{C}$ for 24 to $48 \mathrm{~h}$. For each plate, the number of colony-forming units of each bacterial species was counted, and a single well-isolated colony was subcultured for bacterial species identification. Pathogens were initially classified according to colony morphologic features, hemolytic characteristics, and Gram stain reaction.

Bacterial species were further identified following conventional procedures. Colonies presumptively identified as staphylococci were tested by the tube coagulase method and deoxyribonuclease degradation test in DNase agar plates. Staphylococcus aureus was identified by a positive coagulase reaction and a positive DNase test. Coagulase-negative staphylococci were identified by a negative coagulase reaction and a negative DNase test (Devriese et al., 1985). Isolates presumptively identified as streptococci were tested for Christie, Atkins, Munch-Petersen (CAMP) test reaction and biochemical properties (SVA Strep, SVA, Uppsala, Sweden). Gram-negative isolates were classified as Escherichia coli when positive for the production of $\beta$-D-glucuronidase and indole (PI Test, SVA). Strains that were negative were further tested by the API20E identification system (bioMérieux SA, Marcy l'Etoile, France), which permits a rapid species identification of Enterobacteriaceae and other gram-negative organisms (Oliver et al., 2004).

Somatic cell count was determined using a Combifoss 5300 cell counter (Foss Electric, Hillerød, Denmark). To approximate the normal distribution, data were expressed as natural logarithm of SCC in thousands $/ \mathrm{mL}$ (LnSCC; 1,000 cells $/ \mathrm{mL}$ ).

Selenium in pasture and concentrate was evaluated by inductively coupled plasma mass spectroscopy (Hill Laboratories, Hamilton, New Zealand). The content of Se was measured in milligrams per kilogram of dry matter.

The effective amount of Se delivered to the cows, on a per cow per day basis, was estimated by multiplying the average pasture, silage, and concentrate DMI by their average Se concentration. Mean Se concentration was $0.035 \mathrm{mg} / \mathrm{kg}$ of $\mathrm{DM}$ and $0.1 \mathrm{mg} / \mathrm{kg}$ of $\mathrm{DM}$ for pasture and concentrate, respectively. The effective amount of Se delivered to the cows via the depot injection of barium selenate was not evaluated. However, an early trial conducted in the United Kingdom indicated that the release of Se from the site of injection is not constant over time, estimating the payout of Se from a single depot injection to be, on average, $0.8 \mathrm{mg}$ of Se/d (95\% CI: $0.28,1.27 \mathrm{mg}$ of Se/d) in heifers (Mallinson et al., 1985). Authors arrived at this estimate by measuring the residual barium selenate at the site of injection 17 wk after treatment.

The Se intake recommended, on a per cow per day basis, for intensive dairy systems (NRC, 2001) and 
for extensive pasture-based systems in New Zealand (Grace, 1992; Wichtel, 1998a) was extrapolated by multiplying the estimated DMI by the suggested Se concentration in the ration. Based on these assumptions, recommended daily Se intake was estimated at 4.7 and $0.6 \mathrm{mg}$ of $\mathrm{Se} / \mathrm{cow}$ per day for the intensive and extensive management systems, respectively.

Selenium status was evaluated through activity of GPx by using a kinetic method (Ransel, Randox Laboratory, Crumlin, UK); GPx is a Se-containing enzyme currently used as a biomarker of Se status. The method used approximates an early methodology (Paglia and Valentine, 1967) with slight modifications (Davidson et al., 1990). Briefly, hemoglobin in fresh blood was measured by the cyanomethemoglobin method before GPx analysis. Readings of blood GPx activity were made in a Cobas Mira chemistry analyzer (Roche Diagnostics GmbH, Mannheim, Germany). The enzyme activity is proportional to the decrease in absorption at $340 \mathrm{~nm}$ after oxidation of NADPH into NADP (Davidson et al., 1990). The enzyme activity was measured in units per gram of hemoglobin, considering an activity below $100 \mathrm{U} / \mathrm{g}$ of $\mathrm{Hb}$ as indicator of suboptimal Se status (Ceballos et al., 1999).

\section{Definition of IMI}

A culture was considered positive when $\geq 1 \mathrm{cfu} / 0.025$ $\mathrm{mL}$ (equivalent to $\geq 40 \mathrm{cfu} / \mathrm{mL}$ ) of a pathogen was obtained. A quarter was considered to have an IMI in the first week after calving when the same pathogen was cultured from both duplicate samples. After calving, an IMI was considered when the quarter was culture-positive for the same pathogen in 2 out of 3 consecutive samples (Zadoks et al., 2001, with slight modifications).

During lactation, a quarter was considered to have a new IMI when a pathogen was cultured in any of the following cases:

1. A culture-negative quarter in the first week after calving that met the IMI criteria after wk 3 .

2. An infected quarter, past wk 3 , that was negative for the previous 2 samples.

3. An infected quarter, past wk 3 , that met the IMI criteria but for a different pathogen.

A previously infected quarter was considered recovered from IMI for a bacterial species if none of the above definitions were met and the sample was free of the pathogen on at least 2 consecutive tests (Zadoks et al., 2001, with slight modifications). Samples containing more than 2 bacterial species were considered contaminated, and were not informative of IMI status.
The duration of an IMI was expressed based on the number of calendar days that the quarter was positive. Thus, a positive quarter on one test was positive for 14 d (Smith et al., 1984). The number of recovered (i.e., cured) quarters, according to the previous IMI definition, was also recorded.

\section{Statistical Analysis}

Incidence Risk of New IMI. The pathogenspecific incidence risk of new IMI was calculated as the probability that an individual quarter had a new IMI during lactation. To evaluate the incidence risk of new IMI, the quarter of the cow was the unit of interest, and only quarters free of infection with the pathogen of interest at calving were included in the analysis. The effect of Se supplementation on this variable was evaluated using a logistic regression model, with a random cow effect (Dohoo et al., 2009). The resulting model was as follows:

$$
\operatorname{logit}\left(\mathrm{p}_{i}\right)=\beta_{0}+\beta_{1} \text { treatment }_{(i)}+u_{i}
$$

where $\beta_{0}$ is the constant, $\beta_{1}$ is the regression coefficient for treatment effect, and $u_{i}$ is the cow random effect. The coefficients of the regression were expressed as odds ratio.

Incidence Rate of New IMI. The pathogenspecific incidence rate was defined as the number of new quarter infections with the pathogen of interest per quarter-time period at risk (with time period being a 14-d interval). Consequently, quarter-time at risk for a new pathogen-specific IMI was calculated as the total time (i.e., number of 14-d intervals) minus the number of intervals that a quarter had an IMI with that specific pathogen. The unit of interest for the analysis of incidence rate was the quarter of the cow. The effect of Se supplementation was evaluated using a Poisson regression model (Dohoo et al., 2009), accounting for cows as a random variable with the number of new pathogenspecific IMI as the outcome, and quarter-time at risk as the offset. The resulting model was as follows:

$$
\operatorname{Ln}[\mathrm{E}(I)]=\beta_{0}+\beta_{1} \text { treatment }_{(i)}+u_{i},
$$

where $\operatorname{Ln}[\mathrm{E}(I)]$ is the natural logarithm of the expected value of the incidence rate of IMI ( $I=$ number of new infections/number of time periods at risk), $\beta_{0}$ is the constant, $\beta_{1}$ is the regression coefficient for treatment effect, and $u_{i}$ is the cow random effect. The coefficients of the regression were expressed as incidence rate ratio. Analyses were carried out using the statistical software Stata release 11.0 (Stata Corp., College Station, TX). 
SCC and GPx. The repeated measurements of LnSCC and GPx (d 0 to 270 posttreatment) on each cow were analyzed separately using linear mixed models with a random cow effect (Dohoo et al., 2009). Different within-cow correlation structures were evaluated. Results from first-order autoregressive (AR1), first-order autoregressive moving average (ARMA 1,1), and Toeplitz were compared by likelihood-ratio tests. The effects of supplementation and time (month for LnSCC and days for GPx), as well as their interaction, accounting for cows as random effects were evaluated. The resulting model for LnSCC or blood GPx activity in cow $\mathrm{i}$ within treatments at time $\mathrm{j}$ was as follows:

$$
\begin{gathered}
\mathrm{y}_{i j}=\mu+\alpha_{\text {treatment }(i)}+\beta_{j}+(\alpha \beta)_{\text {treatment }(i), j} \\
+\mathrm{A}_{i}+\varepsilon_{i j},
\end{gathered}
$$

where $\mathrm{y}_{i j}$ corresponds to LnSCC or blood GPx activity; $\mu$ is the overall mean; $\alpha_{i}$ is the treatment effect; $\beta_{j}$ represents the effect of time (month for LnSCC or days for GPx); $(\alpha \beta)_{i j}$ is the interaction between treatment and time; $\mathrm{A}_{i}$ is the random cow effect; and $\varepsilon_{i j}$ is the error term. The models were evaluated by examining the standardized residuals, and transformations of the outcome were explored whenever the model assumptions were not fully met. The optimal correlation structure for the within-cow dependence was autoregressive moving average for the analysis of LnSCC, with an estimated baseline correlation of $0.97(\mathrm{SE}=0.01)$, which decreased by a factor of $0.73(\mathrm{SE}=0.04)$ for each month of separation. Therefore, an estimated correlation 1 mo apart was $0.97 \times 0.73=0.71$. The model validation did not reveal any noncompliance with model assumptions. With regard to GPx, the optimal correlation structure for the within-cow dependence was Toeplitz with correlations of $0.35,0.07,-0.48$, and -0.59 .

Analyses were carried out using the statistical software SAS version 9.2 (SAS Institute Inc., Cary, NC).

\section{RESULTS}

The mean period from the start of the trial to calving was $62 \mathrm{~d}$ (95\% CI: 57, 66). One cow in the control group died 10 wk before drying-off, but data were kept for the statistical analyses because the cause of death was not related to udder health. All milk samples from one supplemented cow collected over the 10-mo period were not suitable for SCC analysis because they were clotted.

Mean parity of the supplemented and unsupplemented cows was $2.5 \pm 1.4$ and $2.1 \pm 1.4$, respectively, ranging from 1 to 5 across both groups. Daily milk yield was
$19.0 \pm 0.65$ and $20.6 \pm 0.62 \mathrm{~kg} / \mathrm{d}$ for supplemented and unsupplemented cows, respectively $(P=0.08)$.

Statistical analysis showed a strongly significant effect of the interaction between supplementation with barium selenate and days after the treatment $(P<$ 0.001). Blood GPx activity was significantly higher in the supplemented group from $30 \mathrm{~d}$ after the injection with barium selenate, which was the first sampling after the injection (Figure 1). The highest activity was observed $90 \mathrm{~d}$ after the treatment, being $235 \mathrm{U} / \mathrm{g}$ of $\mathrm{Hb}(95 \%$ CI: $203,268 \mathrm{U} / \mathrm{g}$ of $\mathrm{Hb})$ higher than that observed in unsupplemented control cows (Figure 1).

Selenium delivered to the cows was compared on a per cow per day basis to the recommended daily intakes. The basal Se intake in both groups of cows was approximately $0.9 \mathrm{mg}$ of $\mathrm{Se} / \mathrm{cow}$ per day, which corresponded to approximately $20 \%$ of the amount recommended by NRC. However, the basal Se intake was $160 \%$ of the amount recommended for dairy cows raised in pastoral systems.

\section{IMI and Clinical Mastitis}

At calving, 17 of 196 quarters (8.7\%) had an IMI. During lactation, 3,936 milk samples were collected for bacteriologic analysis, of which $3,141(79.8 \%)$ were culture-negative and $7(0.2 \%)$ were contaminated. Pathogens were isolated in $788(20.0 \%)$ milk samples, with Corynebacterium bovis $(53.3 \%)$, Staph. aureus (21.4\%), and CNS (19.4\%) being the most common isolated pathogens.

A total of 100 new IMI were found in both groups of cows, 58 in supplemented cows, and 42 in the control cows. The duration of IMI ranged from 14 to $165 \mathrm{~d}$ in the supplemented cows and from 32 to $154 \mathrm{~d}$ in the unsupplemented cows. A total of 165 quarters were cured (Table 1). The proportion of cured quarters in the supplemented cows $(24.0 \%)$ was similar to that observed in the unsupplemented group $(15.0 \%$; $P=$ 0.11 ).

The odds of new IMI during lactation, although numerically higher in the supplemented group, was not different between supplemented and unsupplemented cows (Table $2 ; P=0.17$ ). The odds of pathogen-specific IMI was similar between groups. Parity did not affect the overall odds of IMI or the pathogen-specific IMI odds (Table 2).

The overall incidence rate of new IMI during lactation was 0.011 and 0.008 new IMI per 14-d interval at risk for supplemented and unsupplemented cows, respectively $(P=0.15)$. The pathogen-specific incidence rate ratio was also similar between groups, and the parity of the cow did not affect the incidence rate ratio of new IMI during lactation (Table 3). 


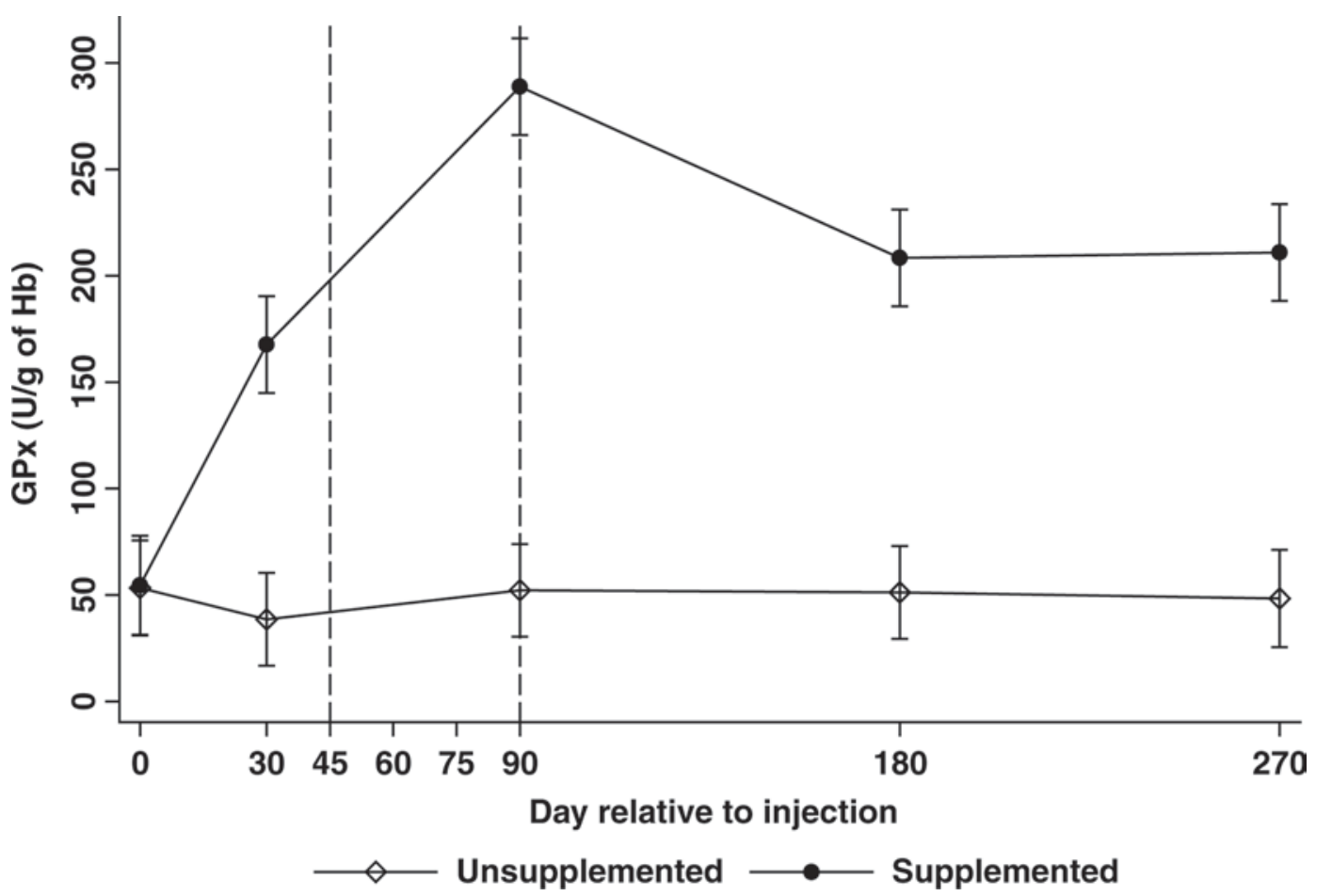

Figure 1. Mean $( \pm \mathrm{SE})$ of activity of glutathione peroxidase $(\mathrm{GPx})$ in blood in pasture-based dairy cows that were either supplemented with barium selenate before calving $(\mathrm{n}=24)$ or left unsupplemented $(\mathrm{n}=25)$. Dashed vertical lines indicate beginning and end of the calving period in relation to the time of treatment with barium selenate. Differences between groups were statistically significant from d 30 onward $(P$ $<0.001)$.

At calving, no cases of clinical mastitis were detected in the supplemented cows, whereas one case was found in the unsupplemented group. During lactation, 18 cases were detected, 8 of them in the supplemented cows and 10 in the control cows. However, the odds of getting clinical mastitis during lactation was not associated with supplementation (odds ratio: 0.84, 95\% CI: $0.19,3.61)$ or parity $(P=0.95)$.

\section{SCC}

Somatic cell count increased steadily from the first month of lactation to drying-off in both groups $(P<$ 0.001; Figure 2). Geometric mean SCC in the first month of lactation was 29,000 cells/mL compared with 148,000 cells $/ \mathrm{mL}$ in the last sample before drying-off.

Table 1. Number of quarters with an IMI at calving, new infections, and their duration in quarters of lactating pasture-based dairy cows injected with barium selenate before calving $(\mathrm{n}=24)$, compared with unsupplemented control cows $(\mathrm{n}=25)$

\begin{tabular}{|c|c|c|c|c|c|c|c|c|}
\hline Pathogen & \multicolumn{4}{|c|}{ Supplemented } & \multicolumn{4}{|c|}{ Unsupplemented } \\
\hline Staphylococcus aureus & 5 & 9 & $165(21,259)$ & 4 & 3 & 10 & $42(28,182)$ & 5 \\
\hline Streptococcus uberis & 0 & 2 & 70 & 0 & 0 & 1 & 42 & 1 \\
\hline Streptococcus bovis & 1 & 2 & $35(28,42)$ & 2 & 1 & 1 & $32(28,35)$ & 1 \\
\hline Streptococcus spp. & 0 & 5 & $28(14,42)$ & 5 & 0 & 1 & 84 & 1 \\
\hline
\end{tabular}

${ }^{1} \mathrm{C}=$ number of infections at calving.

${ }^{2} \mathrm{~L}=$ number of new IMI during lactation.

${ }^{3}$ Duration of the infection in the quarter (median, and lower and upper quartiles).

${ }^{4}$ Number of cured quarters. 
Table 2. Effect of selenium supplementation on the overall odds or pathogen-specific odds of IMI in pasturebased dairy cows injected with barium selenate before calving $(\mathrm{n}=24)$ compared with unsupplemented control cows $(\mathrm{n}=25)$

\begin{tabular}{lcc}
\hline Item & Odds ratio $(95 \% \mathrm{CI})$ & $P$-value \\
\hline Overall & $2.31(0.69,7.80)$ & 0.17 \\
Parity (number of lactations) & Baseline & 0.51 \\
1 & $0.48(0.06,4.04)$ & 0.50 \\
2 & $1.57(0.45,5.52)$ & 0.48 \\
$>2$ & $0.74(0.14,3.95)$ & 0.73 \\
Pathogen & $1.04(0.06,16.88)$ & 0.98 \\
Staphylococcus aureus & $1.60(0.02,129.20)$ & 0.83 \\
Streptococcus dysgalactiae & $2.11(0.19,23.60)$ & 0.55 \\
Streptococcus uberis & $5.90(0.54,64.40)$ & 0.14 \\
Streptococcus bovis & $1.73(0.62,4.82)$ & 0.30 \\
Streptococcus spp. & $1.96(0.50,7.61)$ & 0.33 \\
Escherichia coli & & \\
CNS & & \\
Corynebacterium bovis & & \\
\hline
\end{tabular}

${ }^{1}$ No infections in unsupplemented cows.

Supplementation did not affect SCC, nor was there an interaction between treatment and time. Geometric mean SCC was 76,000 and 87,000 cells/mL for supplemented and unsupplemented cows, respectively $(P=$ $0.68)$. Neither parity $(P=0.72)$ nor its interaction with treatment was associated with $\operatorname{LnSCC}(P=0.52)$.

\section{DISCUSSION}

Activity of GPx was higher in supplemented than in unsupplemented cows by the time of the first posttreatment sample (30 d after treatment), remaining higher in treated cows for the rest of the study. Blood GPx activity has much laboratory-to-laboratory variation; therefore, our results were compared with reference values obtained using the same method, reflecting an adequate Se status based on Chilean reference ranges (Ceballos et al., 1999). However, this difference did not translate into enhanced udder resistance to pathogens.
No differences between groups for the incidence rate of new IMI were observed. Somatic cell count significantly increased in both groups until the end of the trial, not being affected by Se supplementation.

Blood activity of GPx varies with Se intake; therefore, its evaluation as a biomarker of Se status is useful, giving a good indication of the incorporation of Se into functional selenoproteins (Arthur, 1999; Grace et al., 2001). In our study, basal Se intake of cows was lower than the $4.7 \mathrm{mg} / \mathrm{cow}$ per day recommended by NRC (2001). However, the single injection of barium selenate before calving contributed an undetermined daily amount of supplemental Se that was sufficient to cause a substantial difference in blood GPx activity between groups. These results concur with other studies indicating a steady increase in GPx activity after the injection of barium selenate (Grace et al., 2001). There is a delay between supplementation and the increase in blood GPx activity, which results from the incorpora-

Table 3. Effect of selenium supplementation on the incidence rate (IR) of new IMI in pasture-based dairy cows injected with barium selenate before calving $(\mathrm{n}=24)$ compared with unsupplemented control cows $(\mathrm{n}=25)$

\begin{tabular}{lcc}
\hline Item & IR $(95 \% \mathrm{CI})$ & $P$-value \\
\hline Overall & $1.36(0.83,2.22)$ & 0.22 \\
Parity (number of lactations) & Baseline & 0.52 \\
1 & $0.69(0.25,1.85)$ & 0.46 \\
2 & $1.18(0.71,1.95)$ & 0.53 \\
$>2$ & $1.97(0.38,10.20)$ & 0.42 \\
Pathogen & $1.02(0.06,16.26)$ & 0.99 \\
Staphylococcus aureus & $1.34(0.03,66.73)$ & 0.88 \\
Streptococcus dysgalactiae & $2.05(0.18,22.61)$ & 0.56 \\
Streptococcus uberis & $6.42(0.59,70.20)$ & 0.13 \\
Streptococcus bovis & & \\
Streptococcus spp. & $1.96(0.65,5.93)$ & 0.23 \\
Escherichia coli & $1.73(0.62,4.86)$ & 0.30 \\
CNS & & \\
Corynebacterium bovis & &
\end{tabular}

${ }^{1}$ No offset for infections in unsupplemented cows. 


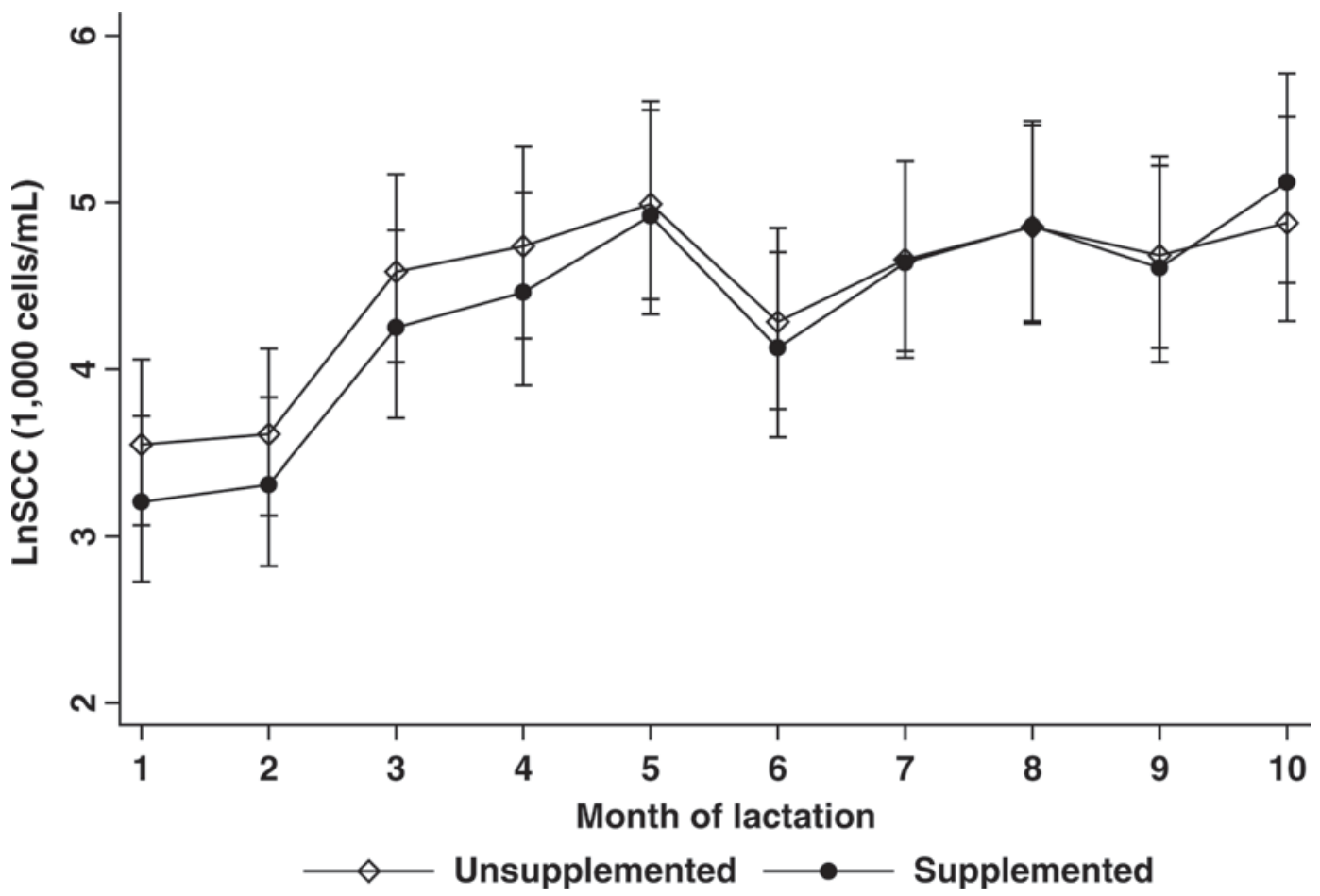

Figure 2. Mean $( \pm \mathrm{SE})$ of natural logarithm of somatic cell counts $(\mathrm{LnSCC} ; \times 1,000$ cells $/ \mathrm{mL})$ in milk of pasture-based dairy cows that were either supplemented with barium selenate before calving $(\mathrm{n}=23)$ or left unsupplemented $(\mathrm{n}=25)$. Differences between the supplementation groups were not statistically significant; the effect of time was significant $(P<0.001)$.

tion of Se into the enzyme during erythropoiesis (Grace et al., 2001). In this trial, the long-acting Se preparation increased blood GPx activity for up to $270 \mathrm{~d}$ after treatment.

Few trials have examined the dynamics of IMI in Se-supplemented cows compared with unsupplemented cows during their corresponding follow-up periods. Of those that appear in the peer-reviewed literature, all have been in intensively managed confined herds and have observed a negative association between Se status and the incidence of IMI (Smith et al., 1985; Malbe et al., 1995). Selenium supplementation was highly protective in one study, translating into fewer coliform and staphylococcal IMI (i.e., 91\% were CNS, and isolated coagulase-positive staphylococci were Staph. hyicus or Staph. intermedius) at calving, fewer cases of clinical mastitis, shorter duration of infections, and lower milk SCC in Se-supplemented primiparous cows; however, no differences in the rate of IMI were observed during lactation (Smith et al., 1985). Malbe et al. (1995) reported a reduction of both the prevalence of IMI and high SCC when mid-lactation cows in intensive systems were fed with either inorganic or organic Se $(0.2 \mathrm{mg}$ of $\mathrm{Se} / \mathrm{kg}$ of DM). Even though the cows of our study had a lower basal Se intake, we did not observe any effect of Se supplementation on the risk of IMI during lactation, in agreement with the results reported by Smith et al. (1985). We have not found reports on the dynamics of IMI comparing Se-supplemented and unsupplemented cows under pastoral systems comparable to our study.

In the present study, geometric mean SCC increased steadily from the beginning to the end of the trial, similar to what was described previously (Schepers et al., 1997). Within a lactation, geometric mean SCC of uninfected cows is affected by the amount of milk produced (Schepers et al., 1997); the increasing mean SCC with increasing DIM will therefore partly be the result of a decreasing milk production during lactation. Additionally, SCC at the end of lactation will be affected by a higher prevalence of IMI, which increases with the stage of lactation (Weller et al., 1992; Schepers et al., 1997).

Observational studies and trials in the United States (Smith et al., 1985; Erskine et al., 1987; Weiss et al., 1990) and Estonia (Malbe et al., 1995) suggest a negative relationship between plasma Se or blood GPx and SCC. Our results did not support those findings, agreeing with other studies that found no association between either an adequate Se status (Grace et al., 1997; Nyman et al., 2008) or Se supplementation (Coe et al., 1993; Bourne et al., 2008) and SCC. In New Zealand studies with pasture-based dairy cows supplemented with 
barium selenate (Whelan et al., 1992) or intraruminal pellets containing Se (Wichtel et al., 1994), researchers did not observe a reduction of SCC in the milk of supplemented cows, suggesting that giving supplemental Se beyond the estimated requirement may not offer further advantage to reduce the risk of new IMI or SCC under these management conditions.

Discrepancies between the results presented herein and those of researchers in other regions, particularly in the United States, may be explained by a variety of nonnutritional and nutritional factors other than Se intake. First, a nonnutritional factor might be study design, as our design had sufficient power to detect a difference of 40,000 cells $/ \mathrm{mL}$ and a reduction of $40 \%$ in the risk of new IMI between groups, but the obtained data did not reflect such differences between groups. A second reason might be related to the presence of other dietary factors that may interact with Se requirements, such as the intake of vitamin E (NRC, 2001). Most cows in pastoral dairy systems will experience sufficient intake of vitamin $\mathrm{E}$ when fresh forage is fed, and a higher vitamin $\mathrm{E}$ intake appears to have a sparing effect on Se (Wichtel, 1998b); however, this relationship has not been quantified (NRC, 2001) and may be affected by the consumption of fatty acids in the ration (Wichtel et al., 1996). Clearly, when Se intake is lower than recommended values, vitamin $\mathrm{E}$ influences the incidence and severity of mastitis in dairy herds (Weiss et al., 1997).

A third possible reason relates to differences in the pathogen challenge between intensive and pastoral systems. The pathogen challenge during this study might have been insufficient (in type or degree), compared with the challenges in other studies, to demonstrate a difference between groups in resistance to IMI. Early studies on the effect of Se supplementation and udder health started with a higher prevalence of IMI at calving compared with the prevalence observed in our cows, and were focused on the effect of Se supplementation on the incidence of environmental mastitis (Smith et al., 1984, 1985), because confinement favors IMI by environmental pathogens. The number of new IMI caused by environmental pathogens, in particular $E$. coli, was low in our study. Finally, another concern in the current study design may be related to the fact that supplemented and unsupplemented cows were pastured and milked together -if one of the groups has an increased incidence of IMI, this might influence the incidence in the other group. However, if a difference in udder health had been found and the cows had not been pastured and milked together, this difference could very well have been the result of other factors that were different between the 2 groups of cows.

Whether NRC (2001) recommendations for Se intake are applicable under southern Chilean conditions is uncertain. However, under the conditions of our experiment, the inadequacy in Se intake did not appear to be a significant factor in the susceptibility to IMI, and cows on pasture in southern Chile probably have Se requirements, at least for optimal udder immunity, that are no higher than the actual intakes of the unsupplemented control cows in our study.

\section{CONCLUSIONS}

Supplementation using a long-duration injection of barium selenate in pasture-based dairy cows increased blood GPx activity. However, this difference in Se status did not translate into differences in the risk of new IMI or SCC pattern. Discrepancies with previously published results on the effect of Se supplementation on udder health may be related to variations in the requirement of Se for dairy cows in pastoral systems compared with the current recommendation for cows in intensive systems. Under the conditions of this study, Se supplementation before calving did not result in improved measures of udder health in the subsequent lactation, indicating that Se basal intake in cows from southern Chile seemed to be adequate for preventing subclinical mastitis.

\section{ACKNOWLEDGMENTS}

The Direction of Research of Universidad Austral de Chile financed this study (Grant DID-UACH S-200752). The authors thank Agrícola Nuss Ltd., managers and milkers of Los Pellines dairy farm, and E. Ewertz for their support and assistance. The comments and suggestions made by Ruth N. Zadoks (Moredun Research Institute, Midlothian, UK) are gratefully acknowledged.

\section{REFERENCES}

Arthur, J. R. 1999. Functional indicators of iodine and selenium status. Proc. Nutr. Soc. 58:507-512.

Bourne, N., D. C. Wathes, K. E. Lawrence, M. McGowan, and R. A. Laven. 2008. The effect of parenteral supplementation of vitamin $\mathrm{E}$ with selenium on the health and productivity of dairy cattle in the UK. Vet. J. 177:381-387.

Burton, J. L., and R. J. Erskine. 2003. Immunity and mastitis. Some new ideas for an old disease. Vet. Clin. North Am. Food Anim. Pract. 19:1-45.

Ceballos, A., F. G. Wittwer, P. A. Contreras, E. Quiroz, and H. L. Böhmwald. 1999. [Blood activity of glutathione peroxidase and its correlation with blood selenium concentration in grazing dairy cattle]. Pesq. Agropec. Bras. 34:2331-2338.

Coe, P. H., J. Maas, J. Reynolds, and I. Gardner. 1993. Randomized field trial to determine the effects of oral selenium supplementation on milk production and reproductive performance of Holstein heifers. J. Am. Vet. Med. Assoc. 202:875-881.

Davidson, W. B., D. G. Kennedy, P. J. Hughes, and W. J. Blanchflower. 1990. The stability of glutathione peroxidase activity in plasma 
from cattle, pigs and sheep on storage in the presence and absence of glutathione. Vet. Res. Commun. 14:441-446.

Devriese, L. A., K. H. Schleifer, and G. O. Adegoke. 1985. Identification of coagulase-negative staphylococci from farm animals. J. Appl. Bacteriol. 58:45-55.

Dohoo, I. R., W. Martin, and H. Stryhn. 2009. Veterinary Epidemiologic Research. 2nd ed. VER Inc., Charlottetown, PEI, Canada.

EMEA. 1999. Committee for veterinary medicinal products, barium selenate. http://www.emea.europa.eu/pdfs/vet/mrls/058099en. pdf Accessed Apr. 24, 2009

Erskine, R. J., R. J. Eberhart, L. J. Hutchinson, and R. W. Scholz. 1987. Blood selenium concentrations and glutathione peroxidase activities in dairy herds with high and low somatic cell counts. J. Am. Vet. Med. Assoc. 190:1417-1421.

Grace, N. D. 1992. The determination of the selenium requirements of dairy cattle. Page 106-111 in Proc. New Zealand Trace Elements Group Conference, Palmerston North. Massey Univ., Palmerston North, New Zealand.

Grace, N. D., K. L. Ankenbauer-Perkins, A. M. Alexander, and R. M. Marchant. 2001. Relationship between blood selenium concentration or glutathione peroxidase activity, and milk selenium concentrations in New Zealand dairy cows. N. Z. Vet. J. $49: 24-28$.

Grace, N. D., S. Knowles, and J. Lee. 1997. Relationships between blood Se concentrations and milk somatic cell counts in dairy cows. N. Z. Vet. J. 45:171-172.

Grasso, P. J., R. W. Scholz, R. J. Erskine, and R. J. Eberhart. 1990. Phagocytosis, bactericidal activity, and oxidative metabolism of milk neutrophils from dairy cows fed selenium-supplemented and selenium-deficient diets. Am. J. Vet. Res. 51:269-274.

Huijps, K., T. J. Lam, and H. Hogeveen. 2008. Costs of mastitis: Facts and perception. J. Dairy Res. 75:113-120.

Ibeagha, A., E. Ibeagha-Awemu, J. Mehrzad, and X. Zhao. 2007. Selenium, immune functions and health of dairy cattle. Pages 289 303 In Nutritional biotechnology in the feed and food industries: Proceedings of Alltech's 23rd annual symposium. T. P. Lyons, K. A. Jacques, and J. M. Hower, ed. Nottingham University Press, Nottingham, UK.

MacPherson, A., and J. S. Chalmers. 1984. Methods of selenium supplementation of ruminants. Vet. Rec. 115:544-546.

Malbe, M., M. Klaassen, W. Fang, V. Myllys, M. Vikerpuur, K. Nyholm, S. Sankari, K. Suoranta, and M. Sandholm. 1995. Comparisons of selenite and selenium yeast feed supplements on Se-incorporation, mastitis and leucocyte function in Se-deficient dairy cows. J. Vet. Med. A 42:111-121.

Mallinson, C. B., W. Allen, and B. Sansom. 1985. Barium selenate injections in cattle: Effects on selenium concentrations in plasma and liver and residues at site of injection. Vet. Rec. 117:405407.

Maus, R. W., F. A. Martz, R. L. Belyea, and M. F. Weiss. 1980 Relationship of dietary selenium to selenium in plasma and milk from dairy cows. J. Dairy Sci. 63:532-537.

Ndiweni, N., and J. M. Finch. 1995. Effects of in vitro supplementation of bovine mammary gland macrophages and peripheral blood lymphocytes with alpha-tocopherol and sodium selenite: implications for udder defences. Vet. Immunol. Immunopathol. $47: 111-121$

NRC. 2001. Nutrient Requirements of Dairy Cattle. 7th ed. Natl. Acad. Press, Washington, DC.

Nyman, A. K., U. Emanuelson, K. Holtenius, K. L. Ingvartsen, T. Larsen, and K. P. Waller. 2008. Metabolites and immune variables associated with somatic cell counts of primiparous dairy cows. J Dairy Sci. 91:2996-3009.

Oliver, S. P., R. N. Gonzalez, J. S. Hogan, B. M. Jayarao, and W. E. Owens. 2004. Microbiological procedures for the diagnosis of bovine udder infection and determination of milk quality. 4th ed. Natl. Mastitis Counc., Verona, WI.

Paglia, D. E., and W. N. Valentine. 1967. Studies on the quantitative and qualitative characterization of erythrocyte glutathione peroxidase. J. Lab. Clin. Med. 70:158-169.

Schepers, A. J., T. J. Lam, Y. H. Schukken, J. B. Wilmink, and W. J. Hanekamp. 1997. Estimation of variance components for somatic cell counts to determine thresholds for uninfected quarters. J. Dairy Sci. 80:1833-1840.

Smith, K., J. Harrison, D. Hancock, D. Todhunter, and H. Conrad. 1984. Effect of vitamin $\mathrm{E}$ and selenium supplementation on incidence of clinical mastitis and duration of clinical symptoms. J. Dairy Sci. 67:1293-1300.

Smith, K. L., H. R. Conrad, B. A. Amiet, and D. A. Todhunter. 1985. Incidence of environmental mastitis as influenced by dietary vitamin E and selenium. Kieler Milchw. Forsch. 37:482-486.

Smith, K. L., J. Hogan, and W. Weiss. 1997. Dietary vitamin E and selenium affect mastitis and milk quality. J. Anim. Sci. 75:1659 1665 .

Sordillo, L. M., and S. L. Aitken. 2009. Impact of oxidative stress on the health and immune function of dairy cattle. Vet. Immunol. Immunopathol. 128:104-109.

Weiss, W. P., J. S. Hogan, K. L. Smith, and K. H. Hoblet. 1990. Relationships among selenium, vitamin E, and mammary gland health in commercial dairy herds. J. Dairy Sci. 73:381-390.

Weiss, W. P., J. S. Hogan, D. A. Todhunter, and K. L. Smith. 1997. Effect of vitamin E supplementation in diets with a low concentration of selenium on mammary gland health of dairy cows. J. Dairy Sci. 80:1728-1737.

Weller, J. I., A. Saran, and Y. Zeliger. 1992. Genetic and environmental relationships among somatic cell count, bacterial infection, and clinical mastitis. J. Dairy Sci. 75:2532-2540.

Whelan, N. C., R. A. Bruce, D. H. Samson, A. M. Alexander, and J. B. Tasker. 1992. Evaluation of the production-enhancing effects of Deposel in a dairy herd with marginal selenium deficiency. Proc. Soc. Sheep and Beef Cattle Vet. N. Z. Vet. Assoc. 22:33-42.

Wichtel, J. J. 1998a. A review of selenium deficiency in grazing ruminants. Part 2: Towards a more rational approach to diagnosis and prevention. N. Z. Vet. J. 46:54-58.

Wichtel, J. J. 1998b. A review of selenium deficiency in grazing ruminants. Part 1: New roles for selenium in ruminant metabolism. N. Z. Vet. J. 46:47-52.

Wichtel, J. J., A. L. Craigie, H. Varela-Alvarez, and N. B. Williamson. 1994. The effect of intra-ruminal selenium pellets on growth rate, lactation and reproductive efficiency in dairy cattle. N. Z. Vet. J. $42: 205-210$.

Wichtel, J. J., D. A. Freeman, A. L. Craigie, H. Varela-Alvarez, and N. B. Williamson. 1996. Alpha-tocopherol, selenium and polyunsaturated fatty acid concentrations in the serum and feed of spring-calving dairy heifers. N. Z. Vet. J. 44:15-21.

Zadoks, R. N., H. G. Allore, H. W. Barkema, O. C. Sampimon, G. J. Wellenberg, Y. T. Gröhn, and Y. H. Schukken. 2001. Cow- and quarter-level risk factors for Streptococcus uberis and Staphylococcus aureus mastitis. J. Dairy Sci. 84:2649-2663. 